\title{
Performance analysis of pressurized irrigation systems operating on-demand using flow-driven simulation models
}

\author{
M.J. Calejo ${ }^{a}$, N. Lamaddalena ${ }^{b}$, J.L. Teixeira ${ }^{\text {c }}$, L.S. Pereira ${ }^{\text {c,* }}$ \\ ${ }^{a}$ COBA, SA - Avenida 5 de Outubro, 323, 1600-011 Lisboa, Portugal \\ ${ }^{\mathrm{b}}$ CIHEAM, Istituto Agronomico Mediterraneo, 70010 Valenzano-Bari, Italy \\ ${ }^{c}$ Agricultural Engineering Research Center, Institute of Agronomy, Technical University of Lisbon, Tapada da Ajuda, 1349-017 Lisboa, Portugal
}

\section{A R T I C L E I N F O}

Article history:

Received 12 June 2007

Accepted 15 September 2007

Published on line 5 November 2007

Keywords:

Irrigation system performance

Hydrants characteristics

Indexed characteristic curves

Relative pressure deficit

Reliability

Steady-state modelling

\begin{abstract}
A B S T R A C T
On-demand pressurized irrigation systems are designed to deliver water with the flow rate and pressure required by the farm irrigation systems, sprinkling or micro-irrigation, and respecting the time, duration and frequency decided by the farmers. Due to the variation in farm demand along the season and the day, a large spatial and temporal variability of flow regimes occurs in these systems, which may affect the performance of the farm systems and the yields of the irrigated crops. Therefore, there is a need to analyse those systems to identify and solve performance problems. In this research, two simulation models for the analysis of irrigation systems operating on-demand, ICARE and AKLA, are used and compared to assess the hydraulic performance of the irrigation network of the Lucefecit Irrigation System, in Southern Portugal. ICARE assesses the global performance of the irrigation system through the indexed characteristic curves, while AKLA provides for the identification of the relative pressure deficit and reliability at every hydrant. Both models adopt a flow-driven analysis approach, performing the analysis for multiple flow regimes. To support the hydraulic characterization of the system and for calibration of the steadystate hydraulic model, field measurements were performed at selected nodes of the network, including four hydrants. The analysis with ICARE does not provide for a sufficient identification of problems. In fact, poor performance is indicated when a few hydrants operate below the minimum pressure set at design. Differently, the analysis with AKLA, applied at the hydrant level, shows that the performance of the Lucefecit system is generally acceptable. AKLA identifies which hydrants operate below the required pressure and, therefore, allows to support any eventual related improvement. Results show that the performance of the system highly improved when changing the piezometric elevation from 260 to $265 \mathrm{~m}$ a.s.l. However, this improvement is not sufficient because three hydrants still have high relative pressure deficit and low reliability. Solutions for those hydrants require increasing diameters of network pipes supplying them.
\end{abstract}

(C) 2007 Elsevier B.V. All rights reserved.

\section{Introduction}

Pressurized irrigation systems operating on-demand deliver water with the flow rate and pressure required by farm irrigation systems, sprinkling or micro-irrigation, and with time duration and frequency decided by the farmers. Therefore, they allow farmers to operate their irrigation systems with a large freedom with respect to other types of delivery

\footnotetext{
* Corresponding author. Tel.: +351 213621575; fax: +351 213621575.

E-mail addresses: mjc@coba.pt (M.J. Calejo), lamaddalena@iamb.it (N. Lamaddalena), jlteixeira@isa.utl.pt (J.L. Teixeira), lspereira@isa.utl.pt (L.S. Pereira).
} 
schedules. The water delivery nodes of a pressurized irrigation network consist of hydraulic valves, usually designated as hydrants, which are generally equipped with flow and pressure regulators. The nominal discharge at a hydrant is then supposed to be independent of the pressure. Hydrants' discharges are set at the design phase according to the size of the field, the type of on-farm irrigation systems, crop water requirements and, more recently, taking into consideration the variable decisions of farmers relative to the time duration and frequency of irrigations and the farmer's behaviour (Pereira et al., 2003; Moreno et al., 2007). Systems are designed to assure that the pressure at all hydrants is equal or greater to the minimum pressure set at design, to assure appropriate functioning of the on-farm systems (Labye et al., 1988; CEMAGREF, 1990; Lamaddalena, 1997; Lejano, 2006).

Sizing these systems requires careful selection of design discharges and pressure regulation and an optimization of the pipe network (CEMAGREF, 1990; Planells et al., 2001, 2007; Theocharis et al., 2006). Discharges flowing into each section may be computed by using probabilistic approaches in which the Gaussian distribution of discharges is hypothesized (Clément, 1966; Clément and Galand, 1979). With these methods a risk threshold is accepted, i.e. during the operation of the system, discharges higher than those assumed at design may occur with low probability. Alternatively, discharges may be generated through the simulation of the demand by performing the water balance at level of each hydrant combined with a stochastic approach to take into consideration the farmers' behaviour, i.e. that farmers' irrigation decisions vary relative to the assumptions made at design (Lamaddalena, 1997; Calejo et al., 2005; Khadra and Lamaddalena, 2006; Moreno et al., 2007). Then design may be performed using several flow regimes as proposed by Labye et al. (1988).

Usually just one flow regime, computed from the First Clément formula (Clément, 1966), is used to design collective irrigation systems operating on-demand. This approach does not permit to take into consideration the variety of flow regimes occurring in a collective irrigation system. In fact, hydrant pressure depends on the conditions at the upstream end - discharge demand and upstream piezometric head - and on the combination of the hydrants operating simultaneously, what is usually referred to as hydrants' configuration. Lamaddalena (1997) and Lamaddalena and Pereira (1998) demonstrated that, even when the design discharges are not exceeded, very low hydraulic performance could occur in the system during its operation due to the seasonal and daily variation in farm demand. Consequently, a large spatial and temporal variability of pressure and discharge available at the hydrants may occur and affect network performance and even crop yield (Pereira, 1999; Lamaddalena et al., 2007). Consequently, there is a need to examine the performance of on-demand pressurized irrigation systems (Bethery et al., 1981; Lamaddalena and Sagardoy, 2000).

A few models have been developed to analyse the performance of pressurized water distribution networks, either assuming steady-state flow conditions, such as the ICARE (CTGREF, 1979, Bethery, 1990) and the AKLA models (Lamaddalena, 1997; Lamaddalena and Sagardoy, 2000), or considering unsteady flow, like the FLUCS model (Lamaddalena and Pereira, 2007b) and EPANET (Rossman, 2000), this one after convenient adaptations. Their application requires a detailed characterization of the network and data concerning the discharges and piezometric elevations at the upstream end of the network relative to the peak demand period, when the variation of flow regimes is higher and insufficient pressure at hydrants is more likely to occur.

Both ICARE and AKLA models assume the flow rate delivered by each hydrant within an irrigation system is known and constant (flow-driven analysis). This is true when the hydrants are equipped with flow limiter and pressure reducing valve; and when the total discharge of the hydrants operating simultaneously is smaller than the discharge at the upstream flow limiter. When these assumptions are not met, a pressure-driven model is required (Lamaddalena and Pereira, 2007b) for analysis. Field studies were, therefore, performed to verify if the pressurized network of the Lucefecit system, Southern Portugal, satisfies those flow assumptions, and then apply the ICARE and AKLA models to analyse the network performance, which is the main objective of this study.

\section{The models}

\subsection{The ICARE model}

ICARE (CTGREF, 1979; Bethery et al., 1981; Bethery, 1990) bases the analysis on the concept of configuration of hydrants simultaneously in operation, said hydrants' configuration, and assumes that any operating hydrant may deliver the nominal discharge, $d\left(1 \mathrm{~s}^{-1}\right)$. A hydrants' configuration $r$ is defined as a group of operating hydrants $(j)$ that deliver a total discharge Qo $r\left(1 \mathrm{~s}^{-1}\right)$, which cannot exceed the maximal discharge available at the upstream end of the network $Q_{\max }\left(\mathrm{l} \mathrm{s}^{-1}\right)$. Each configuration $r$ is considered to be satisfied when the following condition is true for all the respective hydrants:

$H_{j, r} \geq H_{\min }$

where $H_{j, r}$ is the hydraulic head (m) at the hydrant $j$ within the configuration $r$, and $H_{\min }$ is the minimum required head (m) for appropriate operation of the on-farm irrigation systems supplied by those hydrants.For any discharge $Q_{o r}\left(1 \mathrm{~s}^{-1}\right)$ at the upstream end of the network, different values of the piezometric elevation, $Z_{o r}$ ( $m$ a.s.l.) satisfy Eq. (1). If the couples $\left(Q_{0}\right.$, $\left.Z_{o}\right)_{r}$ are calculated for all possible configurations, $r$, then a cloud of points is obtained in the plane $(Q, Z)$. These points are contained between an upper and a lower envelope: the upper envelope corresponds to $100 \%$ of satisfied configurations, while the lower one concerns a situation where all configurations are not satisfied. Between these two curves, it is possible to define a range of other $\left(Q_{0}, Z_{\circ}\right)$ curves, called indexed characteristic curves, drawn by joining the points having the same percentage of satisfied configurations. The ICARE model computes the indexed characteristic curves for a discrete number of flow regimes, $C$. Thus, for a given $Q_{0}$ $\left(\mathrm{l} \mathrm{s}^{-1}\right)$, and assuming that the discharge delivered by each hydrant is equal to its nominal discharge, the hydrants in 
operation are randomly drawn until the following condition is not satisfied:

$\left|\left(Q_{\mathrm{NH}}\right)_{r}-\mathrm{Q}_{\mathrm{o}}\right| \leq \delta_{\mathrm{t}}$

where $\left(\mathrm{Q}_{\mathrm{NH}}\right)_{\mathrm{r}}$ is the total discharge $\left(1 \mathrm{~s}^{-1}\right)$ corresponding to the number $\mathrm{NH}$ of hydrants in simultaneous operation for the configuration $r$, and $\delta_{\mathrm{t}}$ is the accepted tolerance $\left(\mathrm{s} \mathrm{s}^{-1}\right)$. In general, $\delta_{\mathrm{t}}$ is assumed equal to the value of the smallest hydrant discharge. According to Bethery (1990), the number of configurations, $C$, to be investigated for each discharge should be close to the total number of hydrants of the network.

When testing an irrigation network under flow-driven conditions, it is possible to associate a piezometric elevation at the upstream end of the network to each discharge configuration, such that they satisfy Eq. (1). At the end of the computation, for each value of $Q_{o} r$ there are $C$ values of $Z_{\circ} r$. The performance of the network can be evaluated by the percentage of configurations corresponding to the design $Q_{0}$ and $Z_{\circ}$ that satisfy Eq. (1). However, despite information produced by the indexed characteristic curves, they do not allow the identification of the hydrants that do not satisfy Eq. (1), or evaluating the respective pressure deficits, as discussed by Lamaddalena and Piccinni (1993).

\subsection{The AKLA model}

The AKLA model (Lamaddalena, 1997; Lamaddalena and Sagardoy, 2000) is an improvement relative to ICARE because the hydraulic performance analysis is performed at each hydrant. The model assumes a flow-driven modelling condition, i.e. when irrigation networks are equipped with hydrants where discharge is assumed constant, i.e. independent of changes in pressure within the limits fixed by the respective pressure regulators, and when the sum of the discharges delivered by the hydrants is not higher than the upstream discharge limit. Under these conditions, the model randomly draws a number of hydrants simultaneously operating using a random number generator that follows the uniform statistical distribution. Within each generated configuration $r$, a hydrant (j) is considered satisfied when Eq (1) is true. The model computes the relative pressure deficit at each hydrant, $\mathrm{RPD}_{\mathrm{j}, \mathrm{r}}$, by

$\operatorname{RPD}_{j, r}=\frac{\left(H_{j, r}-H_{\min }\right)}{H_{\min }}$

where $H_{j, r}$ is the hydraulic head $(\mathrm{m})$ at the hydrant $j$ within the configuration $r$, and $H_{\min }$ is the minimum required head as defined above. Thus, $\mathrm{RPD}_{j, r}$ indicates how the pressure available at that hydrant $j$ within the configuration $r$ is close to the target pressure defined when the system is designed. The representation of $\mathrm{RPD}_{\mathrm{j}, \mathrm{r}}$ in a plane where abscises correspond to the nodes' numbering and the ordinates to RPD clearly identifies the hydrants where the pressure head is insufficient.

The AKLA model also computes a reliability indicator that describes how often the system fails (Hashimoto et al., 1982). This criterion is formulated assuming that the performance of an irrigation system can be described by a stationary stochastic process, i.e. the probability distributions describing the time series of pressure heads and discharges at a hydrant do not change with time (Lamaddalena and Pereira, 2007a). If $X_{t}$ is the random variable denoting the state of the system at time $t$, the possible values of $X_{t}$ may be shared into two sets: $S$, relative to the satisfactory conditions, and F, relative to the failure ones. At each instant $t$ the system may fall into one of these two sets. Therefore, the reliability of a system can be described by the probability $\alpha$ that the system is in a satisfactory state, which is given by

$\alpha=\operatorname{Prob}\left[X_{t} \in \mathrm{S}\right]$

From the definition of reliability, the following relationship can be assumed:

$R e_{j}=\frac{\sum_{r=1}^{C} \mathrm{Ih}_{j, r} \mathrm{Ip}_{j, r}}{\sum_{r=1}^{C} \mathrm{Ih}_{j, r}}$

where $\mathrm{Re}_{j}$ is the reliability of the hydrant $j$ and

$\operatorname{Ih}_{j, r} \begin{cases}=1 & \text { if the hydrant } j \text { is open in the configuration } r \\ =0 & \text { if the hydrant } j \text { is closed in the configuration } r\end{cases}$

$\operatorname{Ip}_{j, r} \begin{cases}=1 & \text { if } H_{j, r} \geq H_{\text {min }} \\ =0 & \text { if } H_{j, r}<H_{\text {min }}\end{cases}$

\section{The case study network}

\subsection{Brief characterization of the Lucefecit irrigation system}

The ICARE and AKLA models were applied to the pressurized irrigation network of Lucefecit, south of Portugal, serving 950 ha (Fig. 1) and operating on-demand. The pumping station (EE1) was designed for a discharge $Q_{0}=1153 \mathrm{l} \mathrm{s}^{-1}$ and an upstream piezometric elevation $Z_{o}=260 \mathrm{~m}$ a.s.l. Water is pumped directly into the pipe system (high lift pumps) and two hydro-pneumatic tanks (Smith, 2005) are used to control the pump cycles and to protect the pumping station and the irrigation network from water hammer. In order to assure the minimum required pressure (about $450 \mathrm{kPa}$ ) at the hydrants located in the most unfavourable conditions, a booster pumping station (EE2) serves 14 hydrants located in a terminal branch (Fig. 1). The total number of hydrants is 107. Each hydrant may have 1-4 outlets, with a total number of outlets of 204. The nominal hydrant discharge ranges from 10 to $280 \mathrm{~m}^{3} \mathrm{~h}^{-1}$. Each outlet is equipped with a flow meter and a pressure-discharge regulator.

Field data concerning the irrigation network and hydrants' operation were collected during the irrigation seasons of 20002002. These data were used to assess the design assumption and to calibrate/validate the hydraulic simulation model used in the analysis. Two flow meters (AquaProbe Insertion Type Electromagnetic flow meter) and pressure sensors equipped with data recorders were installed at the upstream end and in a downstream node of the network (Fig. 1). The flow meters were calibrated in the HYDREKA Hydraulics Laboratory using a pressurized pipe and flow velocities ranging $0.13-1.85 \mathrm{~m} \mathrm{~s}^{-1}$. The relative errors of discharges ranges $0.01-1.53 \%$ and those of pressure were of $0.25 \%$. 


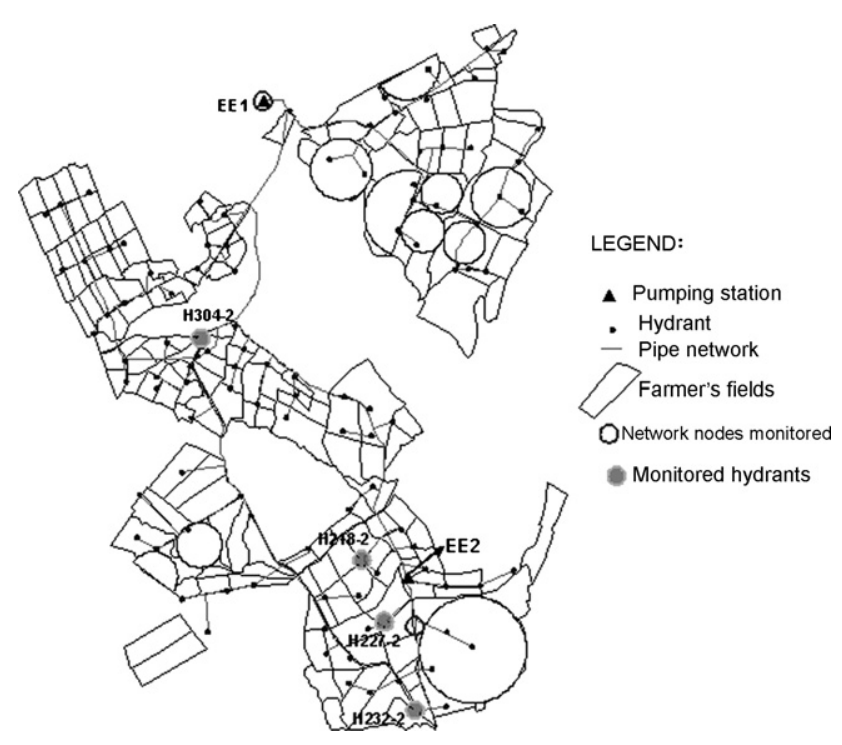

Fig. 1 - The Lucefecit irrigation network.

\subsection{Hydraulic behaviour of the network and hydrants}

The relationship between discharge and pressure at the upstream end of the network (pumping station EE1) is presented in Fig. 2 for the year 2001. Results for 2002 are similar (Calejo, 2003). The design piezometric elevation at the upstream end of the network was $260.00 \mathrm{~m}$ a.s.l., corresponding to a pressure of $944 \mathrm{kPa}$. Results in Fig. 2 show that the upstream pressure is generally larger than the design value. This may cause faster wear and tear of the irrigation pipes in the upstream sections, with consequent increase in hydraulic roughness. Observed data also show that the maximum hourly discharges observed (737 and $656 \mathrm{l} \mathrm{s}^{-1}$ ) in 2001 and 2002, respectively) are considerably smaller than the design discharge $\left(1153 \mathrm{l} \mathrm{s}^{-1}\right.$ ) computed by the First Clément formula, confirming it may be less appropriate as discussed earlier.

The analysis of temporal variations in pressures at the upstream end (Calejo, 2003) show that low pressures occur between 21:00 and 9:00 h during May and June and result from farmers keeping the irrigation outlets open when the pumps are not running at night time. High discharge values associated with low pressure values correspond to mechanical failures of the irrigation pipe network. Data in Fig. 2 also show that the pumping operation is quite unstable for small

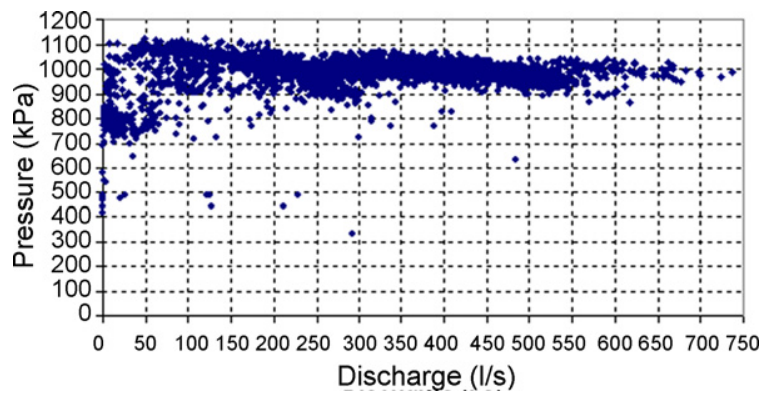

Fig. 2 - Observed pressure and discharge at the upstream end of the network, year 2001 (7676 records).

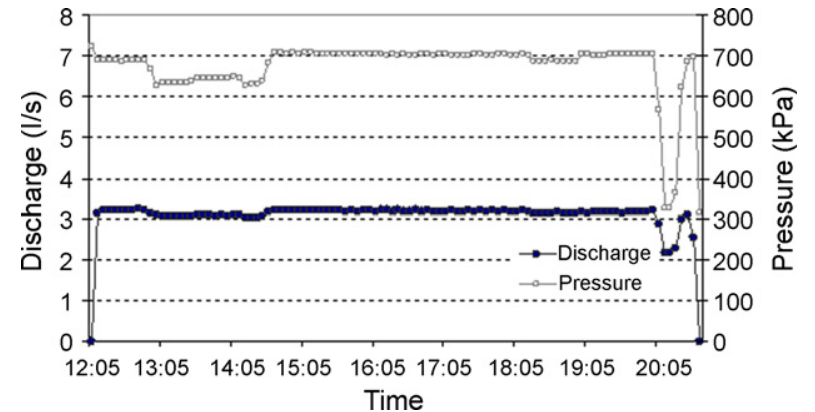

Fig. 3 - Recorded discharge (black dots, below) and pressure (grey dots, above) at the hydrant H218-1, from 12.05 to 20.20 h, June 6, 2001.

discharges $\left(<140 \mathrm{l} \mathrm{s}^{-1}\right)$. Results in Fig. 2, despite data variability, show that the upstream discharge is not dependant on pressure, mainly when the demand is higher. These results, therefore, favour the adoption of a steady-state hydraulic simulation model for performance analysis.

The hydrants are hydraulic valves installed at the nodes of the irrigation system where water is supplied to the farm irrigation systems. The outlets of the hydrants are equipped with flow meters and pressure-discharge regulators (cf. Lamaddalena and Pereira, 2007a) composed of flow limiters and pressure reducing valves. These valves set a constant pressure downstream of the hydrant when the upstream pressure is above the nominal one, and the flow limiters produce a reduction of the flow section area that limits the flow rate to the nominal one, thus causing localized head losses. Therefore, the flow delivered at each hydrant is kept nearly constant and assumed to be independent of the available pressure, which favours the adoption of a flowdriven hydraulic model.

Four hydrants (Fig. 1) were monitored during the irrigation season. Flow meters (type Woltman) with emission of one impulse each $10 \mathrm{l}$ of water withdrawn with a relative error of $2 \%$, and a pressure gauge linked to a data recorder were used for this purpose. Discharge and pressure observed at one monitored outlet of the hydrant $\mathrm{H} 218$ are presented in Fig. 3. Data show that the discharges withdrawn were quite constant during the 8-h period despite the pressure variations recorded during irrigation. A large pressure drop was recorded at the end of the day due to a breakdown in the pumping plant. These conditions of discharge stability do not apply to those hydrants where farmers have asked to remove either the flow limiter or the pressure control valve. This happens when the area served is larger than that foreseen at design, thus requiring a larger discharge, or when particular on-farm irrigation systems (e.g., travelling raingun sprinklers) require a pressure exceeding nominal levels used in the design. These conditions deviate from the flow-driven approach. However, the overall system may be simulated adopting a steady-state hydraulic model as discussed hereafter.

Fig. 4 shows the discharge-pressure relationships relative to hydrant $\mathrm{H} 218$ for the irrigation season of 2001. The head loss characteristic curves, which were produced by the manufacturer and refer to various pressure heads ranging from 600 to 


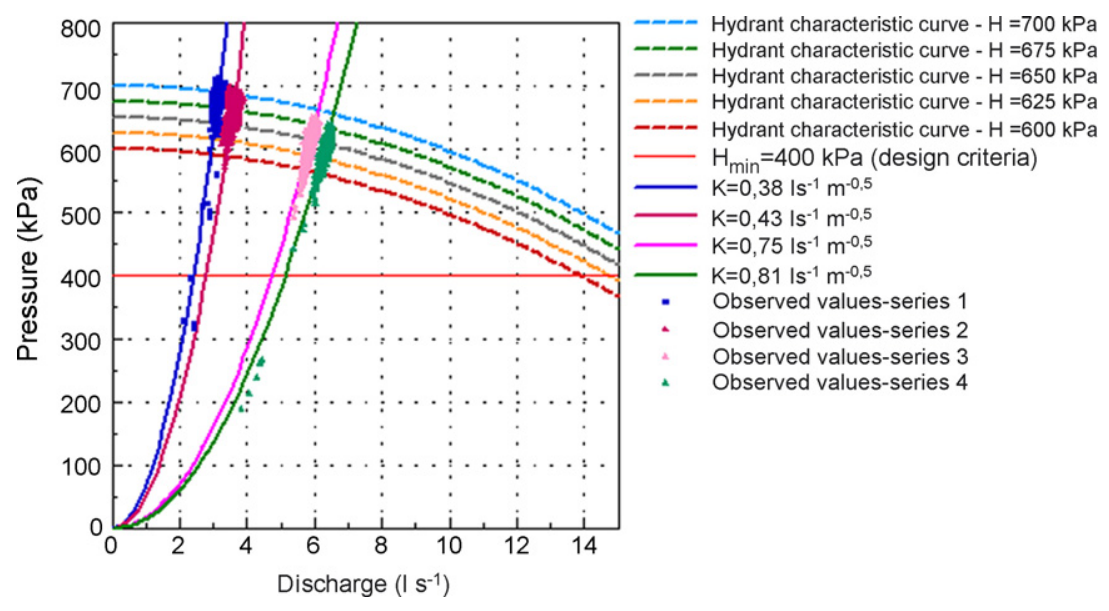

Fig. 4 - Hydrant H218-2: hydrant's head losses characteristic curves for a pressure head ranging 600-700 kPa, and operative discharge-pressure relationships and respective observations relative to four discharges withdrawing.

$700 \mathrm{kPa}$, indicate that the head losses due to the functioning of the pressure-discharge regulators may be relatively high, increasing with pressure head and discharge. This is in fact another reason why farmers ask to have this device removed. Fig. 4 includes the observed operation curves relative to the four farm irrigation systems operating downstream of this hydrant, each one requiring different discharges. These curves were obtained from pressure and discharge observations made during irrigation. These curves are described by the equation:

$Q=K H^{1 / B}$

where $Q$ is the flow rate $\left(1 \mathrm{~s}^{-1}\right), H$ is the pressure head $(\mathrm{m}), B$ is the pressure head exponent ( $B=2$ for a turbulent regime) and $K$ is the discharge coefficient $\left(1 \mathrm{~s}^{-1} \mathrm{~m}^{-1 / B}\right)$. The $\mathrm{K}$ values obtained for the 4 farm systems are $0.38,0.43,0.75$ and $0.81 \mathrm{l} \mathrm{s}^{-1} \mathrm{~m}^{-1 / 2}$, the first two referring to small discharges $\left(<4 \mathrm{l} \mathrm{s}^{-1}\right)$ and the later to larger ones, near $6 \mathrm{l} \mathrm{s}^{-1}$. These results show that discharges delivered by the hydrant to supply the farm systems are not totally independent from the pressure (Eq. (6)). However, the assumption made for adopting a flow-driven approach may be accepted since the respective operation curves are nearly vertical lines in the operating pressure domain (Fig. 4).

\section{Calibration of the steady-state hydraulic model}

The calibration of water distribution models was established by comparison of simulated and observed data and modifying input parameters to match the simulated results to the observed data (Walski, 1983, 1986). Because flow regimes are generally not precisely known in irrigation water distribution systems, the procedure faces several uncertainties, including in relation with the hydrants' hydraulic behaviour.

In this work, the calibration of the hydraulic simulation model was done comparing the simulated head losses with those recorded at the hydrants $\mathrm{H} 218$ and the H232 (Fig. 1) during the peak demand period, when both the hourly discharge and head losses were the greatest. The selection of the hydrants was determined by: (1) the location, as far as possible from the upstream end, (2) the nominal flow because the available measuring devices were suitable for outlets with nominal diameters $\leq 80 \mathrm{~mm}$, (3) the agreement of the farmers to install the equipment and (4) security of the location against vandalism.

Data referring to the periods when irrigation was starting or ending were excluded because discharges are not stable during these periods. Because computations were done assuming steady flow in pipes, the calibration could also serve to confirm the assumption made above about adopting a flow-driven approach for the performance analysis.

For the hydraulic simulation, the head losses, $h_{\mathrm{L}}(\mathrm{m})$, were computed with the Chézy equation. The Chézy's coefficient was obtained from the Bazin relationship (Lencastre, 1987). The calibration parameter was the roughness coefficient of Bazin, $\gamma\left(\mathrm{m}^{0.5}\right)$. Five scenarios for this coefficient, based upon values acceptable in the engineering practice and taking into consideration the aging of the pipes (Lencastre, 1987), were considered to calibrate the model (Table 1).

The head losses observed between the upstream of the network and a given hydrant $j$ are given by

$\sum_{o \rightarrow j} h_{L}=Z_{o}-\left(H_{j}+h_{s}\right)-z_{j}$

where $Z_{o}$ is the piezometric elevation at the upstream end $(\mathrm{m})$, $H_{j}$ is the pressure head observed downstream of the hydrant $j$ $(\mathrm{m}), h_{\mathrm{s}}$ is the head loss at the hydrant due to the pressuredischarge regulator $(\mathrm{m})$ and $\mathrm{z}_{j}$ is the elevation in the axis of the hydrant outlet. $h_{\mathrm{s}}$ was computed from the characteristic curve of the hydrant (e.g. Fig. 5) and is given by

$h_{\mathrm{s}}=\xi_{\mathrm{h}} \mathrm{Q}^{2}$

The value for $\xi_{\mathrm{h}}\left(\mathrm{m}^{-5} \mathrm{~h}^{2}\right)$ is specific to each type of hydrant/ outlet and may be obtained from laboratory experiments or from the manufacturer. Using data from the manufacturer, the value $\xi_{\mathrm{h}}=0.013 \mathrm{~m}^{-5} \mathrm{~h}^{2}$ was adopted. 
Table 1 - Scenarios for the roughness coefficient of Bazin for the pipe network

Material pipes

Material pipes

Cast iron pipes

Asbestos pipes

PVC pipes

Roughness coefficient $\gamma\left(\mathrm{m}^{0.5}\right)$ for various scenarios

$\begin{array}{ccccc}\text { I } & \text { II } & \text { III } & \text { IV } & \text { V } \\ 0.16 & 0.16 & 0.24 & 0.36 & 0.36 \\ 0.10 & 0.10 & 0.10 & 0.16 & 0.16 \\ 0.10 & 0.10 & 0.10 & 0.10 & 0.12\end{array}$

The recorded head loss data were grouped in classes relative to the discharges withdrawn at the upstream end. Fig. 5 refers to hydrant $\mathrm{H} 232$, which is located at the terminal part of the network (Fig. 1); data relative to hydrant H218 (not shown) produced similar average values.

Fig. 6 compares the statistical distribution of head losses at hydrant $\mathrm{H} 232$ computed with the model for 1000 flow regimes and for the five scenarios of the roughness coefficient defined in Table 1, and experimentally measured. Scenarios I-III lead to head losses much smaller than those observed. Scenarios IV and $\mathrm{V}$ better approach field observations, however, underestimating the head losses. The maximum simulated head loss was $21 \mathrm{~m}$, which corresponds to the third quartile of the observed values. Despite these discrepancies, the Bazin roughness coefficients relative to scenario 4 were adopted because these values are commonly used in engineering practice (cf. Lencastre, 1987). Further increases in roughness did not improve the match between predicted and measure values. Walski $(1983,1986)$, discussing the simulation of pipe networks with uncertain roughness and localized head losses, stated that it is not worthwhile to seek a strong concordance between simulated and observed head losses. In the present

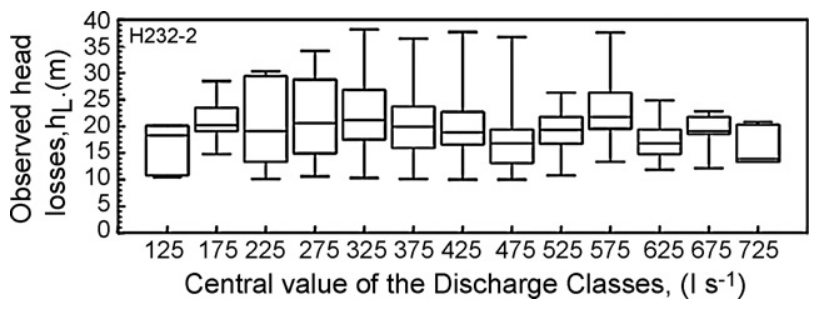

Fig. 5 - Observed head losses between the upstream end and the hydrant H232-2 grouped in classes defined according to the discharges observed at the upstream end of the network.

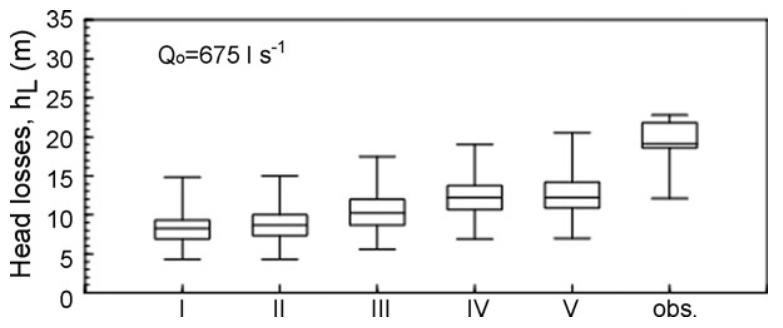

Fig. 6 - Box-whiskers for the head losses simulated between the upstream end of the network and the hydrant H232-2 for five scenarios of the roughness coefficient of Bazin compared with those obtained from field observations. case, the uncertainty was extended to include hydrants head losses. To minimise the impact of such discrepancies, simulations for the performance analysis were oriented to situations in which high head losses did not occur at the hydrants. Results indicate that the AKLA hydraulic simulation model may be further improved relative to hydrants head losses.

\section{Irrigation system performance}

\subsection{Indexed characteristic curves}

The indexed characteristic curves computed with ICARE are presented in Fig. 7. Curves were drawn from data obtained from simulations with 1000 random configurations for the following discharges at the upstream end of the network: 100, $300,400,500,600,700,750$ and $800 \mathrm{l} \mathrm{s}^{-1}$. Results show that for the maximum flow rate recorded at the upstream end (about $750 \mathrm{l} \mathrm{s}^{-1}$ ), the design value for the upstream piezometric elevation $\left(Z_{o}=260 \mathrm{~m}\right.$ a.s.l.) is not sufficient to guarantee a proper overall performance of the system. In fact, the percentage of satisfied configurations is lower than $10 \%$. These results explain why the Lucefecit system managers have increased the upstream pressure to $1000 \mathrm{kPa}$, i.e. $Z_{o}=265 \mathrm{~m}$ a.s.l. For this new $Z_{o}$ the percentage of satisfied configurations increases to near $30 \%$ for the peak discharge, and to near $90 \%$ when the delivered discharge is $\leq 300 \mathrm{l} \mathrm{s}^{-1}$.

Results of the indexed characteristic curves are in agreement with the perception of the system managers and indicate a poor overall hydraulic performance of the Lucefecit irrigation system. However, simulation results do not allow identification of hydrants with pressure deficits and the severity of those localized deficits.

\subsection{Relative pressure deficits}

The relative pressure deficits simulated with AKLA for 2000 flow regimes considering $Q_{o}=750 \mathrm{l} \mathrm{s}^{-1}$ and $Z_{\mathrm{o}}=260 \mathrm{~m}$ a.s.l. are presented in Fig. 8. The unsatisfied outlets having $\mathrm{RPD}_{j, r}<0$ are well identified. Only five outlets show relevant, negative values of $\mathrm{RPD}_{j, r}$. Values of $\mathrm{RPD}_{j, r}<-0.5$ indicate the need for rehabilitation, but simple solutions such as increasing $Z_{o}$ or increasing local pipe diameters could be enough to assure an appropriate system operation. The case of hydrant $\mathrm{H} 223$ (node 216), where $\mathrm{RPD}_{j, r}<1.0$, deserves more attention, since negative pressures may occur in the network, with risk of collapsing. This case is due to the relatively high elevation of the hydrant and to the insufficient internal diameter of the pipe serving it, resulting in a head loss of about $4 \mathrm{~m}$ in the last $266 \mathrm{~m}$. The position and discharge of this hydrant are not in 


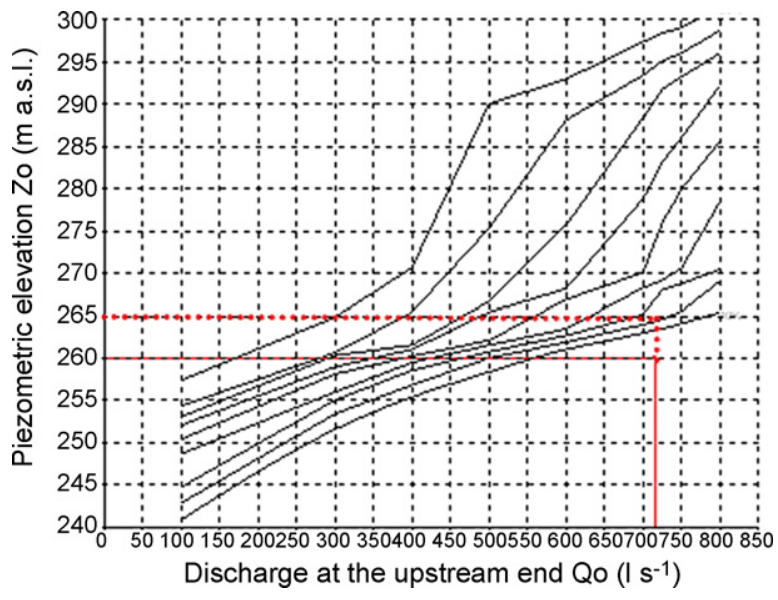

Fig. 7 - Indexed characteristic curves of the Lucefecit irrigation network (the horizontal lines refers to $Z_{o}$ set at design (- ) and actual (- - ), and the vertical one to the maximum observed $Q_{0}$.

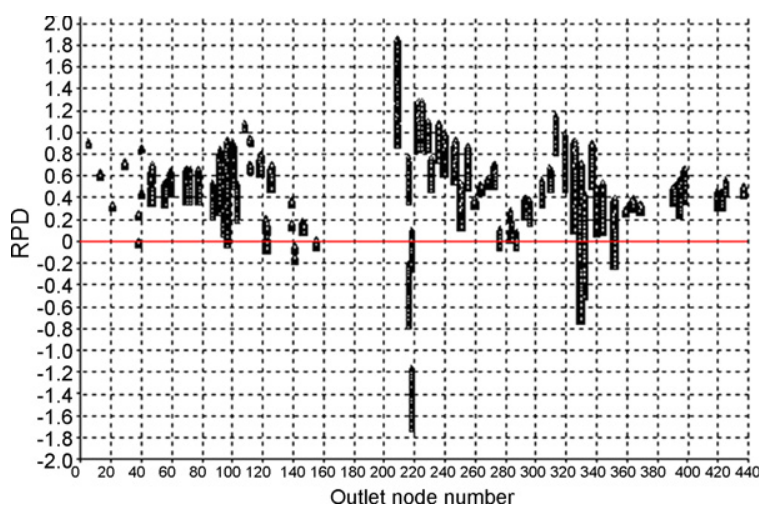

Fig. 8 - Relative pressure deficits at the hydrants of Lucefecit irrigation network simulated with AKLA for 2000 random configurations with $Z_{o}=260 \mathrm{~m}$ a.s.l. and $\mathrm{Q}_{0}=7501 \mathrm{~s}^{-1}$.

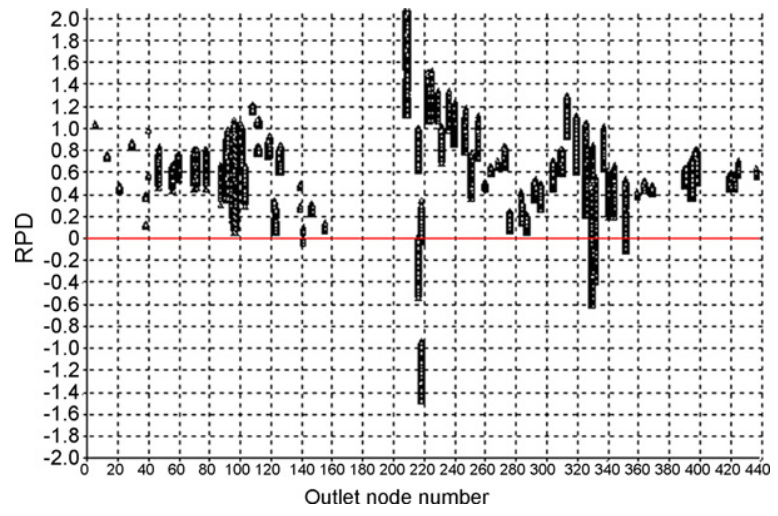

Fig. 9 - Relative pressure deficits at the hydrants of Lucefecit irrigation network simulated with AKLA for 2000 random configurations with $Z_{o}=265 \mathrm{~m}$ a.s.l. and $Q_{0}=7501 s^{-1}$.

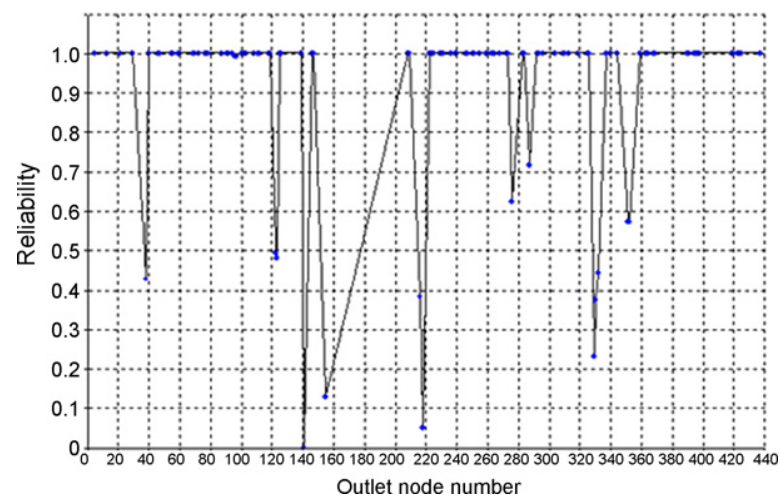

Fig. 10 - Reliability of the Lucefecit irrigation network simulated with AKLA for 2000 random configurations with $Z_{o}=260 \mathrm{~m}$ a.s.l. and $Q_{0}=7501 \mathrm{~s}^{-1}$.

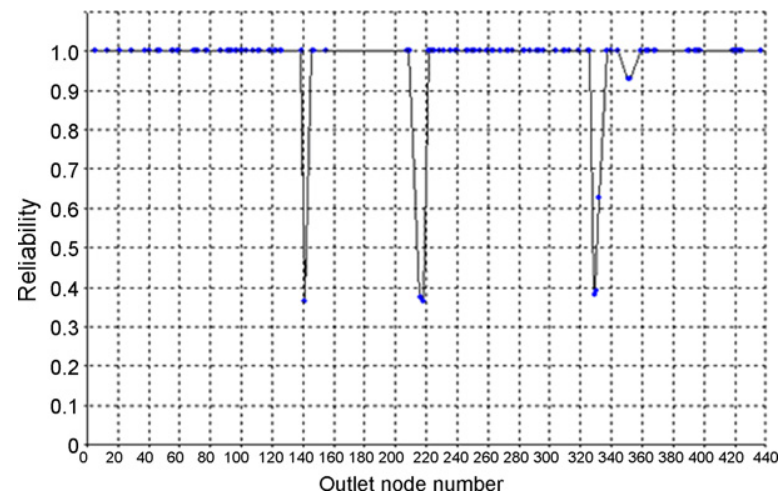

Fig. 11 - Reliability of the Lucefecit irrigaton network simulated with AKLA for 2000 random configurations with $Z_{o}=265 \mathrm{~m}$ a.s.l. and $Q_{0}=7501 \mathrm{~s}^{-1}$.

agreement with the engineering design, and were changed during the construction to satisfy the request of the farmer.

The system managers, considering the identified problems, decided to increase $Z_{o}$ to $265 \mathrm{~m}$ a.s.l. This resulted in an overall improvement, as shown in Fig. 9, where the number of unsatisfied hydrants decreased relative to the design conditions $\left(Z_{o}=260 \mathrm{~m}\right.$ a.s.l., Fig. 8). Most of cases with $\mathrm{RPD}_{j, r}<0$ for the design $Z_{\circ}$ show non-negative RPD values for $Z_{\circ}=265 \mathrm{~m}$ a.s.l. These results agree with those of ICARE (Section 5.1). For $Z_{o}=265 \mathrm{~m}$ a.s.l., only 3 hydrants show $\mathrm{RPD}_{j, r}<-0.5$. However, the hydrant $\mathrm{H} 223$ keeps $\mathrm{RPD}_{j, r}<-1.0$, hence indicating that increasing $Z_{\circ}$ by $5.0 \mathrm{~m}$ was not sufficient during the peak period.

\subsection{Reliability}

System reliability is illustrated in Fig. 10 for $Z_{o}=260 \mathrm{~m}$. Several hydrants have low to very low reliability, with a few having extremely low $\mathrm{Re}$ values. Considering that the reliability indicator describes how often the system fails, these low values indicate that these hydrants have $H_{j}<H_{\text {min }}$ independently of the value of the pressure deficit. Comparing Re and RPD for the hydrant at node 140 indicate that pressure deficits are small but occur extremely often. On the contrary, deficits 
at node 329 are quite important but occur less often than for node 140. Using information from both indicators it is possible to prioritize interventions to progressively solve the malfunctioning of the system.

As for RPD, reliability improves when the piezometric elevation is increased to $Z_{o}=265 \mathrm{~m}$ a.s.l. (Fig. 11). These results show that the decision of project managers to increase $Z_{\circ}$ by $5 \mathrm{~m}$ was appropriate but insufficient for correct operation. Improving the performance of hydrants with low Re requires changing the terminal pipes serving them and/or modifying their location.

\section{Conclusions}

ICARE and AKLA, were useful in evaluating the performance of the pressurized irrigation system of Lucefecit. Data collected at various nodes of the network including at selected hydrants facilitated the understanding of the hydraulic behaviour of the system and of the hydrants, and confirmed the assumption of steady-state flow in the pipe system. Field data was also used to calibrate the hydraulic model relative to the roughness of pipe conduits. Discrepancies observed are likely to be due to uncertainties relative to hydrants' head losses calculations.

Results obtained for the indexed characteristic curves produced with ICARE confirmed the manager's perception of how the network functioned. However, this analysis could not identify the hydrants having low performance. Differently, AKLA generates information on the relative pressure deficit (RPD) and reliability (Re) at the hydrants level. RPD refers to the magnitude of the pressure deficits, and Re determines how often they occur. The results for the Lucefecit irrigation system show that increasing the upstream piezometric elevation from 260 to $265 \mathrm{~m}$ a.s.l. leads to lower pressure deficits and higher reliability. Further improvements require changes in the pipe diameters serving the hydrants with large and frequent pressure deficits.

\section{Acknowledgments}

This study has been performed under national research contracts with PEDIZA and AGRO. A research scholarship funded by the Program PRAXIS XXI of FCT and the support provided by the Lucefecit Irrigation Association and Mr. A. Russel are also acknowledged.

\section{REFEREN C E S}

Bethery, J., 1990. Réseaux Collectifs Ramifiés Sous Pression, Calcul et Fonctionnement. Études Hydraulique Agricole $n{ }^{\circ} 6$. CEMAGREF, Antony.

Bethery, J., Meunier, M., Puech, C., 1981. Analyse des défaillances et étude du renforcement des réseaux d'irrigation par aspersion. Amélioration et Modernisation des Systèmes Existants d'Irrigation et de Drainage (Compte rendus du XI Congrès de la CIID, Grenoble), vol. 1. ICID, New Delhi, pp. 297-324.

Calejo, M.J., 2003. Design and performance analysis of pressurized irrigation systems. Demand Modelling. Two
Case Studies: Lucefecit and Vigia. Ph.D. Thesis. Instituto Superior de Agronomia, Universidade Técnica de Lisboa (in Portuguese).

Calejo, M.J., Teixeira, J.L., Pereira, L.S., Lamaddalena, N., 2005. Modelling the irrigation demand hydrograph in a pressurized system. In: Boaventura Cunha, J., Morais, R. (Eds.), Proceedings of the EFITA/WCCA 2005 Joint Conference on Information Technologies in Agriculture, Food and Environment and Computers in Agriculture and Natural Resources (5th EFITA Conf. and 3rd WCCA, Vila Real), Universidade de Trás-os-Montes e Alto Douro, Vila Real, CD-ROM, pp. 756-770.

CEMAGREF, 1990. Logiciel XERXES-RENFORS, Optimisation Économique des Réseaux Ramifiés Sous Pression, CEMAGREF, Groupement d'Aix-en-Provence.

Clément, R., 1966. Calcul des débits dans les réseaux d'irrigation fonctionnant à la demande. La Houille Blanche 5, 553-575.

Clément, R., Galand, A., 1979. Irrigation par Aspersion et Réseaux Collectifs de Distribution Sous Pression. Eyrolles Editeur, Paris.

CTGREF, 1979. Programme ICARE-Calcul des Caractéristiques Indicées. Note Technique 6, CTGREF Division Irrigation, Aixen-Provence.

Hashimoto, T., Sredomger, J.R., Loucks, D.P., 1982. Reliability, resilience and vulnerability criteria for water resources system performance evaluation. Water Resources Res. 18 (1), 14-20.

Khadra, R., Lamaddalena, N., 2006. A simulation models to generate the demand hydrographs in large-scale irrigation systems. Biosystems Eng. 93 (3), 335-346.

Labye, Y., Olson, M.A., Galand, A., Tsiourtis, N., 1988. Design and Optimization of Irrigation Distribution Networks. Irrigation and Drainage Paper ${ }^{\circ} 44$. FAO, Roma.

Lamaddalena, N., 1997. Integrated simulation model for design and performance analysis of on-demand pressurized irrigation systems. Ph.D. Thesis. Instituto Superior de Agromonia, Universidade Técnica de Lisboa.

Lamaddalena, N., Pereira, L.S., 1998. Performance analysis of on-demand pressurised irrigation systems. In: Pereira, L.S., Gowing, J.W. (Eds.), Water and the Environment: Innovation Issues in Irrigation and Drainage (1st Inter-Regional Conf. Environment-Water, Lisbon), E\&FN Spon, London, pp. 247255.

Lamaddalena, N., Pereira, L.S., 2007a. Assessing the impact of flow regulators with a pressure-driven performance analysis model. Agric. Water Manage. 90 (1), 28-35.

Lamaddalena, N., Pereira, L.S., 2007b. Pressure-driven modeling for performance analysis of irrigation systems operating on demand. Agric. Water Manage. 90 (1), 36-44.

Lamaddalena, N., Piccinni, A.F., 1993. Sull'utilizzo delle curve caratteristiche indicizzate di una rete irrigua per il dimensionamento degli impianti di sollevamento. Rivista di Ingegneria Agrária 3, 129-135.

Lamaddalena, N., Sagardoy, J.A., 2000. Performance Analysis of On-Demand Pressurized Irrigation Systems. Irrigation and Drainage Paper n`59. FAO, Roma.

Lamaddalena, N., Fratino, U., Daccache, A., 2007. On-farm sprinkler irrigation performance as affected by the distribution system. Biosystems Eng. 96 (1), 99-109.

Lejano, R.P., 2006. Optimizing the layout and design of branched pipeline water distribution systems. Irrigation Drainage Systems 20, 125-137.

Lencastre, A., 1987. Handbook of Hydraulic Engineering. Ellis Horwood, Chichester.

Moreno, M.A., Planells, P., Ortega, J.F., Tarjuelo, J., 2007. New methodology to evaluate flow rates in on-demand irrigation networks. J. Irrigation Drainage Eng. 133 (4), 298-306. 
Pereira, L.S., 1999. Higher performance through combined improvements in irrigation methods and scheduling: a discussion. Agric. Water Manage. 40, 153-169.

Pereira, L.S., Calejo, M.J., Lamaddalena, N., Douieb, A., Bounoua, R., 2003. Design and performance analysis of low pressure irrigation distribution systems. Irrigation Drainage Systems 17 (4), 305-324.

Planells, P., Tarjuelo, J.M., Ortega, J., Casanova, M., 2001. Design of water distribution networks for on-demand irrigation. Irrigation Sci. 20 (4), 189-201.

Planells, P., Ortega, J.F., Tarjuelo, J.M., 2007. Optimization of irrigation water distribution networks, layout included. Agric. Water Manage. 88 (1), 110-118.
Rossman, L.A., 2000. EPANET User Manual. US Environmental Protection Agency, Drinking Water Research Division, Risk Reduction Engineering Laboratory, Cincinnaty, Ohio, USA.

Smith, R.S., 2005. Simulation of hydropneumatic tanks in computer pipe network models. J. Hydr. Eng. 131 (10), 909911.

Theocharis, M.E., Tzimopoulos, Ch.D., Yannopoulos, S.I., Sakellariou-Makrantonaki, M.A., 2006. Design of optimal irrigation networks. Irrigation Drainage 55 (1), 21-32.

Walski, T.M., 1983. Technique for calibrating network models. J. Water Resources Plann. Manage. 109 (4), 360-372.

Walski, T.M., 1986. Case study: pipe network model calibration issues. J. Water Resources Plann. Manage. 112 (2), 238-249. 